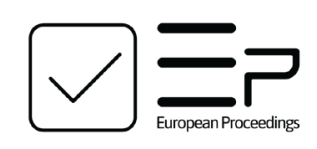

European Proceedings of

International Conference on Education \&

Educational Sciences

EPICEEPSY

www.europeanproceedings.com

e-ISSN: 2672-8141

DOI: $10.15405 /$ epiceepsy.20111.12

$11^{\text {th }}$ ICEEPSY 2020

The International Conference on Education \& Educational Psychology

\title{
UNIVERSITY TEACHERS' RECOGNITION OF THE MELODY OF UNKNOWN FOREIGN LANGUAGES
}

\author{
Petra Besedova (a)*, Simona Beranová (a), Alena Matějovská (a), Jana Žížalová (a) \\ *Corresponding author \\ (a) University of Hradec Králové, Faculty of Education, Rokitanského 62, Hradec Králové, 500 03, Czech Republic, \\ petra.besedova@uhk.cz
}

\begin{abstract}
One of the most interesting spheres in the current linguistic research is the relationship between language and individual beings' mental processes. Memory is one of these processes, and it plays an important role in an individual's life, both in terms of his / her neurophysiological development and of his / her professional growth. With the growing age, memory is increasing and decreasing, and the form of the process of memorizing is also changing qualitatively. Memory is an inseparable component of learning languages. Within its psycholinguistic experiments, the research into language production and perception deals with communicatively based models of language which mainly concern word recognition. In general, it is obvious that a similarity between signals and language representations is compared and estimated in these experiments. Our research applied findings made in this sphere, and it focused on recognizing melodies typical of each language. This paper presents results of the research whose main goal has been to reveal the level of the short-term memory in university teachers through the method of an experiment. The experiment researched the recognition of unknown foreign languages; it focused on the supra-segmental level of the foreign languages. The respondents, 90 university teachers from the Czech Republic, were asked to recognize the melody of the languages played. The results of our research clearly indicate that experience with foreign languages is a certain benefit in the process of recognizing other foreign languages. Music teachers, who are confronted with melodies in general, also have certain advantage when recognizing foreign languages.
\end{abstract}

2672-8141 (c) 2020 Published by European Publisher.

Keywords: Memory, FLT, recognition, cognitive learning. 


\section{Introduction}

The meaning of the word memory is generally well-known; according to Průcha et al. (2009) it is a set of psychological processes which make storage (coding, memorization), retention and recalling of perceptions, knowledge, movements and experience possible. Sternberg (2002) characterizes memory simply as a means through which we go back to our previous experience in order to use this acquired information in the present situation. Neuroscientists and psychologists prefer a broader perspective when giving a definition of memory. From a neuroscientific point of view taken by Hort and Rusina (2007), memory is the ability of animals to store, preserve and process information in the central nervous system. Squire (1987) talks about "adaptive capacity that gives organisms the ability to learn and to remember" (p. 3). In Markowitsch's (2009) opinion, memory is "a repository of ontogenetically acquired learningdependent information that selectively mixes with phylogenetically neuronal structures and can be invoked at any time" (p. 12). Generally, it can be said that we refer to combined changes in the transmission of information in the neural network of an individual being. In the brain, this process enables a large number of biochemical changes at the level of synapses induced by the on-going transformations of bioelectric signals.). This results according to Kulišt'ák (2011), in a more or less permanent storing of all stimuli that the organism consciously or unconsciously receives from its sensory organs. Furthermore, in Heinrichova's (2019) opinion, as he perceives the text, he also experiences the feelings of performers, authors or literary characters, with whom he can subsequently identify.

The basic function of memory is to store, organize and use experience. Nakonečný (2003) adds that it is necessary to point out to the important function of memory in the human psyche - the function to assign a meaning to stimuli and reactions. It means that thanks to memory, we can identify the perceived objects and thus we can identify the activity in question. Over the last thirty years, the concept of so called working memory has spread up. A current prominent British psychologist, Baddeley (2010), gives the following definition of the term: "Working memory refers to the system or systems that are assumed to be necessary in order to keep things in mind while performing complex tasks such as reasoning, comprehension and learning" (p. 136). Working memory is obviously an important issue also in other disciplines interconnected with cognitive science. Memory is involved in all mental abilities, and it is a key factor in the process of learning, where the brain transforms current experience into a code, and further it stores the information in such a way that enables recalling the information later. Human beings need to train their memory to prevent its gradual loss. Memory is also an essential component of the sphere of education, and that is why teachers train their students' memory really every day. But what can be said about the memory of the teachers themselves, and especially university teachers' memory? This issue is discussed in the following text, where we will try to present the results of an experiment that dealt with the recognition of unknown foreign language material by university teachers.

\section{Problem Statement}

According to Průcha (2013), a teacher is a qualified pedagogical worker who is co-responsible for preparation, management, organization and results of the educational process. A teacher is a creator of the teaching environment and classroom climate, an organizer and coordinator of the students' activities, and a manager and evaluator of the learning process. According to Kalhoust and Obst (2002), a teacher is an 
expert who has numerous important automated skills, who is able to sensitively adapt his / her activities to the given situation and context, who can understand situations at a qualitatively deeper level and who can improvise. Memory of teachers, not just university teachers, plays a very important role and should be trained within the framework of every teacher's cognitive training.

Memory is an absolutely essential skill enabling foreign language experience to come into existence. It is a key factor in the learning process, during which the human brain translates current experience into a code. The process of foreign language acquisition is necessarily connected with the human cognitive system, and the acquisition of phonological, lexical and morphosynthetic structures of a foreign language does not take place without the mother tongue being involved. Lachout (2012) adds: "The use of language, by which its production and perception is meant, would not be possible without functional memory. In both the processes, we are forced to use our internal memory, in which we store all the knowledge, experience and information we have acquired. Only thanks to them are we able to understand the language" (p. 80). The same opinion is expressed by Hagoort and Poeppel (2013), who claim that "when listening to speech, the first requirement is that the continuous speech input is perceptually segmented into discrete entities that can be mapped onto, and will activate, abstract phonological representations that are stored in long-term memory" (p. 233). The relationship between memory and foreign language learning can be described as inseparable. During the process of acquiring a foreign language, memory is ubiquitous and learning without it loses its fundamental function. Sinz (1979) claims that "memory is a phenomenon which cannot be separated from learning" (p. 16). We definitely agrre with this opinion.

The individual phases of memory processes from the general point of view and from the foreign language point of view are very similar and are graphically illustrated in Figure 01.

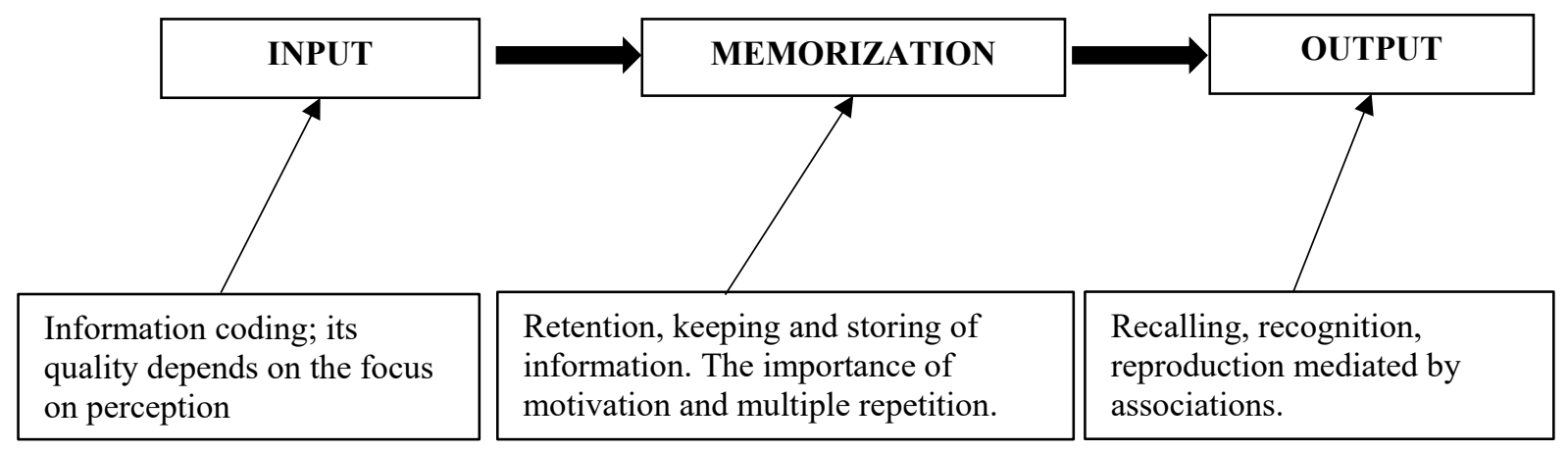

Figure 01. Phases of memory processes

In the first phase, we can speak about the so-called information coding, which results from an active acquaintance with a foreign language material. In this phase, in which the focus on the foreign language perception is important, the foreign language experience of a person is activated on the basis of the connection of new foreign language experiences with those already acquired. If this information is coded in the memory, it is stored in a form of a certain code or representation. Atkinsonová et al. (1995) speaks of the so called visual, acoustic and semantic representation (code). From the foreign language point of view, this phase involves heard, seen and meaning-based information. Each individual then prefers a different type of coding. Unlike the acquisition of vocabulary in the mother tongue, which is usually 
random, the acquisition of vocabulary in a foreign language is intentional. In this case, it is necessary for the new semantic code to be integrated into the existing structure of the individual's mental lexicon. In the second phase, the phase of memorization, which Sedlák and Váňová (2013) describe as retention or storage of information in memory, the information is hierarchically grouped according to different keys. This phase requires the motivation of the individual, which results in a better reception and processing of information. During the first contact with a newly acquired piece of foreign language information, there is a certain gap in its storing in the individual's memory. Furthermore, the capacity of the short-term memory is significantly limited. An integral part of the memorization phase are multiple repetitions of the vocabulary and grammatical structures of the newly acquired foreign language (or multiple repetitions of a newly heard and then played musical composition). New perceptual patterns are created here, a newly acquired piece of information is connected with the information previously received. Referring to this phase, Sedlák and Ván̆ová (2013) mention two kinds of changes - quantitative changes which relate to the extent and volume of memory, and qualitative ones which relate to the perception and storage of information in the consciousness of an individual being. The last phase, the output, is the recalling of the perceived and experienced information in the form of recognition and reproduction. Foreign language processing can have the character of an immediate reaction, which is often mediated by associations and various mnemonic aids. If certain foreign language information is to be recalled from the memory for the needs of speech reception or production, the memory is activated. The level of this activation is determined, for example, by the frequency of the given word. The quality of memorization and subsequent recalling depends not only on the individual phases of memory processes, but also on other factors, including the perceiving subject, the construction and nature of a foreign language utterance and, last but not least, the learning process, which is crucial for the memorization process. If a piece of information is to be permanently memorized, constant repetition is necessary, and, simultaneously, comprehension is necessary. If these two components do not go hand in hand, memorization is endangered. In other words, memory and comprehension mutually interact and are integral parts of acquiring a foreign language.

As it was claimed by Besedová (2019), it is very important to keep in mind that language memory is very dynamic and is significantly impacted by numerous other factors, such as the arrangement of the text, motivation, emotional accent, perceptual complexity and others. The perception of language focuses on the grammatical structure of the language and on the one hand, and on the other hand it examines the psycholinguistic processes that underlie understanding of speech at a higher level.

\section{Research Questions}

Language memory is affected by a number of factors. This research study is based on two other studies which were published in 2019 and which deal with the research into the levels at which pupils aged 12-15 recognize foreign language materials (Besedová, 2019), and the research into the activation of brain structures and their subsequent responses sensed by the EEG. Comprehensive research is based on the idea that in connection with teaching of foreign languages, acoustic coding to the memory of an individual being is applied.

In this phase, the below given main research question of this study was specified:

RQ: "What is university teachers' success rate in recognizing the melody of unknown foreign languages?" 
Based on studying the Czech and foreign professional literature, and based on interdisciplinary cooperation with leading domestic and foreign experts and based on sub-projects dealing with the role of memory in foreign language teaching, the following hypotheses were defined:

H1: "University teachers involved in teaching of foreign languages have a higher percentage of success in recognizing the melody of unknown foreign languages than university teachers involved in teaching other subjects".

H2: "University teachers involved in teaching music have a higher percentage of success in recognizing the melody of unknown foreign languages than university teachers involved in teaching other subjects".

H3: "University teachers involved in teaching music have a higher percentage of success in recognizing the melody of unknown foreign languages than university teachers involved in teaching foreign languages".

H4: "University female teachers have a higher percentage of success in recognizing the melody of unknown foreign languages than university male teachers".

Appropriate answers to our main research question and discussions referring to our hypotheses will be presented later in the text.

\section{Purpose of the Study}

Short-term memory, which is also called recent or working memory, uses mainly an auditory and visual code. This type of memory is the active part of the memory, and it is used to store information for a short time of a few seconds or, occasionally, of a few minutes. Short-term memory is typically temporary. Koukolík (2000) takes the neuropsychological point of view and claims that working memory consists of three components: the phonological loop, visual-spatial sketch pad and central executive. The first component (the phonological loop) is a system in which audio information of the non-speech and speech characters is stored. If not repeated, this information is lost within two or three seconds. The phonological loop, which works with phonological and audio information, is essential in both the mother tongue and foreign languages, and therefore this component of memory plays an important role in foreign language teaching. The phonological loop is evidently proved, as claimed by Baddeley (2010), by phenomena such as the effects of phonological similarity, of the word length and of articulatory suppression, the transfer of information between systems, and numerous neuropsychological phenomena. Further evidence of the phonological loop involved in memory storage and sound manipulation has been given by research carried out by Paulesu et al. (1993), who used positron emission tomography (PET). Further research which dealt with the storage of audio information was carried out by a team led by Besedová and Vyšata (in Besedová et al., 2019) and used electroencephalography. Audio items are much more difficult to remember, and phenomena like the length of the word or the word phrase have also an important impact. In this case, it is appropriate to require loud irrelevant speech production. When learning new words or word phrases, this speech production should be active so that newly acquired information can be stored in the short-term memory and later in the long-term memory.

The main purpose of the study, i.e. an experiment testing the ability to recognize the melody of unknown languages, resulted from our previous research (Besedová, 2019), and it was impacted by the fact 
that memory is an integral part of learning and teaching of foreign languages. The teaching profession requires the pedagogical competence, which in case of foreign language teachers refers to qualifications in the sphere of foreign language training. At the general level, teachers should be knowledgeable in the sphere of the subject taught by them, they should be competent in pedagogy, methodology, management and diagnostics, and they should have communicative, interventional, personal and other competences. Other specific competences are important for teachers of foreign languages, such as communicative, linguistic, sociocultural, intercultural, literary and methodological ones. Active memory is an integral part of all these competences; therefore it should be trained at any age. University teachers from the Czech Republic were tested in our research. Based on the results of the experiment, we will try to answer our main research question concerning the success rate reached by university teachers in recognizing the melody of unknown foreign languages, and we will try to confirm our hypotheses.

\section{Research Methods}

A combination of several research methods was used in our research. First of all, the method of an experiment was applied, i.e. unknown foreign languages were identified on the basis of the recordings of foreign languages which were also used in the experiment in 2019 (Besedova, 2019). In the memory test, the respondents first listened to a sequence of recordings of the same text consecutively presented in ten foreign languages: Chinese, Danish, Finnish, Japanese, Kazakh, Malay, Greek, Swedish, Turkish and Vietnamese. Then, the respondents listened to one of two sequences of five recordings presented in five out of the ten languages mentioned above. The respondents were asked to identify these five languages on the basis of the previous listening experience. Two sub-sequences of five foreign languages were created. Sequence No. 1: Greek, Turkish, Finnish, Chinese and Vietnamese; and sequence No. 2: Danish, Japanese, Swedish, Kazakh and Malay. The division into sequences resulted from the classification of the languages based on their membership in the so called language families (Besedová et al., 2019, p. 33). In our opinion, the choice of sequence should not have any significant effect on the respondent's success rate in the answers.

Another method applied was the questionnaire method which was revealing the correlations of memorial learning appearing in foreign language learning and music performing. The respondents were divided into three monitored groups - music teachers, foreign language teachers, teachers of the other subjects (see Tab. No. 1).

Table 01. Descriptive factors of the respondents

\begin{tabular}{|l|l|}
\hline Row labels & Sum \\
\hline Music teachers & $\mathbf{3 2}$ \\
\hline Male & 14 \\
\hline Female & 18 \\
\hline Foreign language teachers & $\mathbf{2 1}$ \\
\hline Male & 1 \\
\hline Female & 20 \\
\hline Non music and non-foreign language teachers & $\mathbf{3 7}$ \\
\hline Male & 17 \\
\hline Female & 20 \\
\hline Total sum & $\mathbf{9 0}$ \\
\hline
\end{tabular}


The questionnaire also focused on revealing the degree of the respondents' relationship to music and foreign languages. These items were further monitored, but since they are not relevant for the purpose of this paper, the results will not be published here.

The data of our research were pre-processed in the MS Excell, and the subsequent calculations were performed in the IBM SPSS Statistics 24 Program. First of all, the duplicate detection was performed; the ranges of the metric variables were verified, i.e. the minimum and maximum range is within a theoretically possible range of the monitored scales. Subsequently, calculations of the following descriptive statistics used for the description of the research set were performed: minimum, maximum, average, standard deviation for the variable, gender distribution of the observed group. Calculations were performed to compare the success rate of the individual sequences. The median test and the Kruskal-Walis' test showed that there is no statistically significant difference between the sequences. From Table No. 2 it can be seen that the difference is $0.42 \%$, which is statistically negligible. From this fact it can be concluded that the sequences are equivalent in their value.

Table 02. Different sequences and the resulting success rate

\begin{tabular}{|l|l|}
\hline Row labels & Success rate \\
\hline Sequence 1 & $30.45 \%$ \\
\hline Sequence 2 & $30.87 \%$ \\
\hline Total sum & $\mathbf{3 0 . 6 7 \%}$ \\
\hline
\end{tabular}

Other research methods commonly used in the field of pedagogy were applied - the method of expert assessment, the method of analysis and synthesis of a language text, the method of an interview. These methods are not specified in detail because our research was based mainly on the method of an experiment and the method of a questionnaire.

\section{Findings}

Within the framework of our research study, we formulated four hypotheses which are to be confirmed or refuted. Our findings are presented in Table No. 3.

Table 03. University teachers' success rate in recognizing the melody of unknown foreign languages

\begin{tabular}{|l|l|}
\hline Row labels & Success rate \\
\hline Music teachers & $\mathbf{3 0 . 0 0 \%}$ \\
\hline Male & $28.57 \%$ \\
\hline Female & $31.11 \%$ \\
\hline Foreign language teachers & $\mathbf{3 8 . 1 0} \%$ \\
\hline Male & $20.00 \%$ \\
\hline Female & $39.00 \%$ \\
\hline Non-music teacher and non-foreign language teachers & $\mathbf{2 7 . 0 3 \%}$ \\
\hline Male & $27.06 \%$ \\
\hline Female & $27.00 \%$ \\
\hline Total sum & $\mathbf{3 0 . 6 7 \%}$ \\
\hline
\end{tabular}


The process of testing of our hypotheses brought the following results:

$\checkmark$ H1: "University teachers involved in teaching of foregin languages have a higher percentage of success in recognizing the melody of unknown foreign languages than university teachers involved in teaching other subjects".

Hypothesis No. 1 ("University teachers involved in teaching of foregin languages have a higher percentage of success in recognizing the melody of unknown foreign languages than university teachers involved in teaching other subjects") was confirmed. The highest success rate in recognizing unknown foreign languages was reached by foreign language teachers $(n=38.1 \%$, i.e. from two to five out of five foreign languages were recognized), and the lowest success rate was reached by teachers of other subjects, i.e. nonmusic teachers and non-foreign language teachers $(n=27.03 \%$; i.e. one out of five foreign languages was recognized).

$\checkmark$ H2: "University teachers involved in teaching music have a higher percentage of success in recognizing the melody of unknown foreign languages than university teachers involved in teaching other subjects."

Hypothesis No. 2 ("University teachers involved in teaching music have a higher percentage of success in recognizing the melody of unknown foreign languages than university teachers involved in teaching other subjects.") was also confirmed. Music teachers $(\mathrm{n}=30.0 \%$, i.e. from one to two out of five foreign languages were recognized) were by $3 \%$ more successful than teachers of other subjects $(n=27.03 \%$; i.e. one out of five foreign languages was recognized).

X H3: "University teachers involved in teaching music have a higher percentage of success in recognizing the melody of unknown foreign languages than university teachers involved in teaching foreign languages.“

Hypothesis No. 3 ("University teachers involved in teaching music have a higher percentage of success in recognizing the melody of unknown foreign languages than university teachers involved in teaching foreign languages.") was not confirmed. Foreign language teachers $(n=38.1 \%$, i.e. from two to five out of five foreign languages were recognized) are by $8 \%$ more successful than music teachers $(n=30.0 \%$, i.e. from one to two out of five foreign languages were recognized).

H4: "University female teachers show a higher percentage of success in recognizing the melody of unknown foreign languages than university male teachers.“

Hypothesis No. 4 claiming that female teachers $(\mathrm{N}=32.41 \%)$ show a higher percentage of success in recognizing the melody of unknown foreign languages than male teachers $(\mathrm{N}=27.5 \%)$ can be accepted. The biggest difference appeared in teachers of foreign languages, where females $(n=39.0 \%)$ showed much better results than males $(n=20.0 \%)$. When being tested, they showed the difference of at least one recognized item. The differences are smaller in case of music teachers. Females $(n=31.11 \%)$ showed better results than males $(n=28.57 \%)$, but in the process of testing itself the difference was smaller than one recognized item. In case of teachers of other disciplines, the results are almost identical. Although males (n 
$=27.06 \%)$ show a higher success rate than females $(\mathrm{n}=27.0 \%)$, the difference is not statistically significant. These results are illustrated by Fig. 2:

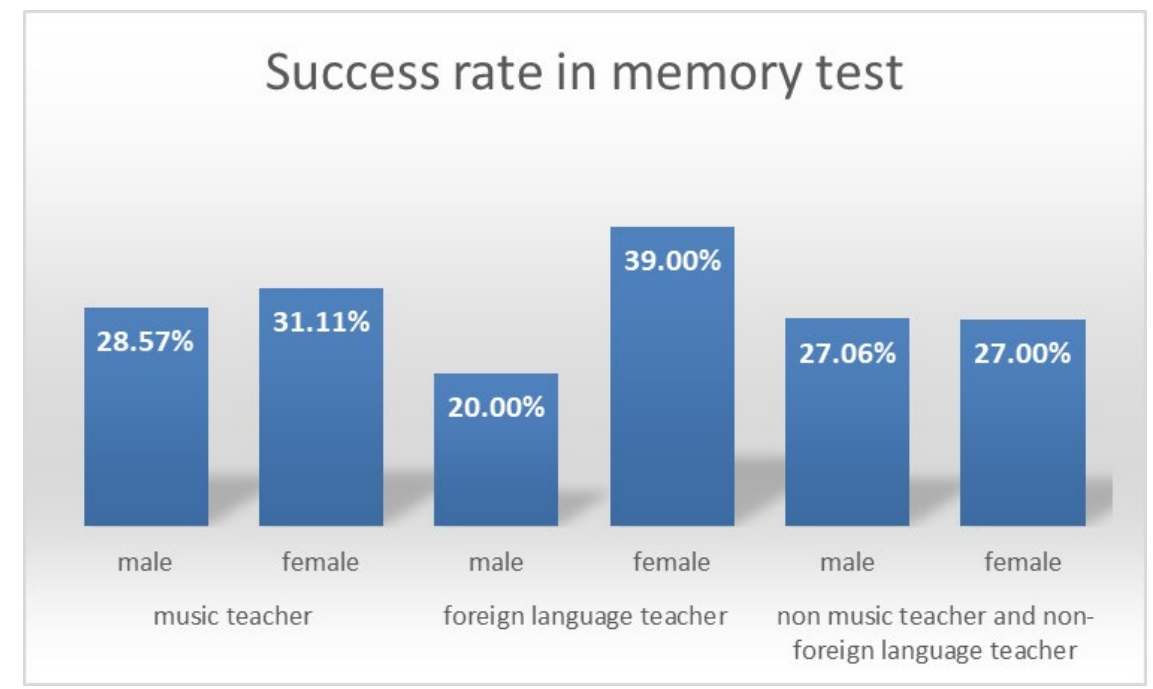

Figure 02. University teachers' success rate in recognizing the melody of unknown foreign languages

This experiment was carried out applying a methodology similar to that used by Besedová in 2019. Fig. 3 presents the results of the last year's research.

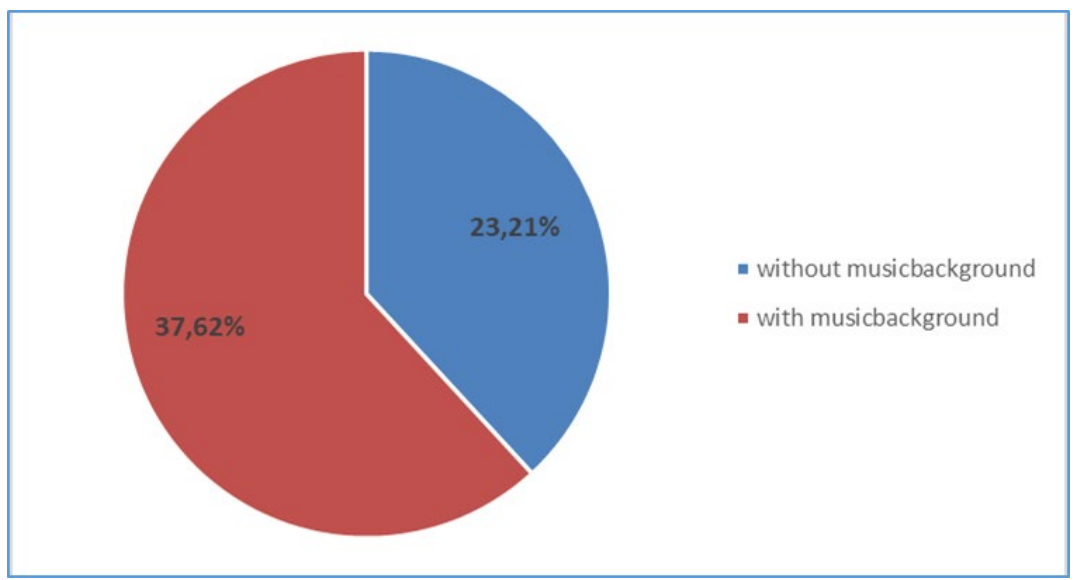

Figure 03. Differences between pupils with / without music background (Besedova, 2019, p. 296)

The results of the study carried out by Besedová in 2019 showed that musically educated students have a higher success rate in memory language tests, and therefore they can be expected to have a higher level of prerequisites for learning foreign languages in comparison with individuals without music education. Our study carried out with university teachers did not result in similar conclusions. In cases of adults, it cannot be claimed that music education plays a significant role or in any way favours individuals in the process of recognizing foreign languages. Our results clearly show a higher success rate reached by foreign language teachers in comparison with music teachers. The answer to our research question: "What is university teachers' success rate in recognizing the melody of unknown foreign languages?" is that the 
success rate is relatively low $(\mathrm{N}=30.67 \%$, i.e. from 1 to 2 out of 5 foreign languages were recognized). In this study research, we monitored the factor of the short-term working memory in university teachers. Focusing on the recognition of unknown foreign languages, we concentrated on suprasegmental phenomena. As this is another partial study in the sphere of research in memory and memorial learning in foreign languages, we are aware of the fact that further research will be needed for making our findings and knowledge coherent.

\section{Conclusion}

A quantitative approach was used to reveal how successful university teachers are when recognizing unknown foreign languages. The method of a questionnaire was used to divide the respondents $(\mathrm{N}=90)$ into three groups (foreign language teachers, music teachers, teachers of other subjects); the issue of the relationship between the success rate and the professional involvement was researched through the first three hypotheses $(\mathrm{H} 1, \mathrm{H} 2, \mathrm{H} 3)$. Foreign language teachers reached the success rate of $\mathbf{3 8 . 1 \%}$; music teachers reached the percentage of $\mathbf{3 0 . 0} \%$; the success rate of teachers of other subjects was $\mathbf{2 7 . 0 3 \%}$. These results clearly demonstrate that experience with learning and teaching of foreign languages is beneficial for memorizing the melody of unknown foreign languages. Foreign language teachers have demonstrated the best abilities for recognizing unknown foreign languages. Our hypothesis claiming that music teachers will show a higher success rate when recognizing unknown foreign languages was based on the assumption that music-trained individuals have better distinctive abilities in the sphere of recognizing supra-segmental phenomena of languages, mainly the melody phenomenon. Our research and its results did not confirm this hypothesis, as music teachers showed the success rate $8 \%$ lower than foreign language teachers did. Another monitored factor was the difference between males and females. Hypothesis No. 4 (H4) referred to this issue, and it assumed that the success rate would be higher for females than for males. We tested the hypothesis, and the results showed that females reached the value of $\mathbf{3 1 . 1 1 \%}$ and males that of $\mathbf{2 8 . 5 7 \%}$, which clearly confirmed our hypothesis. The most successful group in our testing were female teachers of foreign languages, who, with 39\% success rate, recognized at least two out of five foreign languages.

Overall, university teachers of foreign languages are more successful in recognizing unknown foreign language material than university teachers involved in teaching other subjects. Knowledge of foreign languages is beneficial, which was clearly reflected in the memory test.

The procedure chosen by us for testing the success rate in the recognition of unknown foreign languages seems informatively convenient. The method of an experiment confirmed that the respondents who are educated in foreign languages reach a higher success percentage in recognizing foreign languages than respondents not trained in foreign languages. That is why our research question "What is university teachers' success rate in recognizing the melody of unknown foreign languages?" can be answered in the following way: The rate of success depends on the fact whether the particular human being has or has not been trained in foreign languages. At this point, we can also refer to Sapir-Whorf's linguistic relativity, in which Sapir (1964) claims that "we see, hear and otherwise experience very largely as we do because the language habits of our community predispose certain choices of interpretation" (p. 69). Language affects the way in which we encode and store information in our memory, as well as we retrieve this information from our memory. Memory training is an important life-long process, and it is an inseparable part of 
university teachers' profession. The relationship between memory and foreign language learning can be described as inseparable and life-long lasting. In the process of acquiring a foreign language and its subsequent maintaining, memory is ubiquitous. The processes of learning and teaching without memory involvement lose their own fundamental function at any age.

\section{Acknowledgments}

The research was financially supported by a grant of the Specific research of the Faculty of Education of the University of Hradec Kralove (No. 2123/01360/1210). The research was approved by the Ethical Commission of the Faculty of Education of the University of Hradec Kralove on January $22^{\text {nd }} 2019$.

\section{References}

Atkinsonová, R. L., Atkinson, R. C., Smith, E. E., Bem, D. J., \& Nolen-Hoeksema, S. (1995). Psychologie. Victoria Publishing.

Baddeley, A. (2010). Working memory. Current Biology, 20(4), 136-140.

Besedová, P. (2019). Correlation of memorial learning in foreign languages and music. Comparative study of elementary school learners in the Czech Republic. The European Proceedings of Social and Behavioural Science, LXXII, 289-298.

Besedová, P., Ondráková, J., Tauchmanová, V., \& Drtina, R. (2019). Korelace Hudební A Jazykové Paměti: Pilotní studie. Media4u Magazine, 16(4).

Besedová, P., Vyšata, O., Mazurová, R., Kopal, J., Ondráková, J., Vališ, M., \& Procházka, A. (2019). Classification of brain activities during language and music perception. Signal, Image and Video Processing, 13(8), 1559-1567.

Hagoort, P., \& Poeppel, D. (2013). The Infrastructure of the Language-Ready Brain. In M. A. Arbib (Ed.), Language, Music, and the Brain. A Mysterious Relationship. MIT Press.

Heinrichova, N. (2019). Learning history through stories about East Germany. The European Proceedings of Social and Behavioural Science, LXXII, 435-443.

Hort, J., \& Rusina, R. (2007). Pamět' a její poruchy. Pamět’ z hlediska neurovědního a klinického. Maxdorf.

Kalhoust, Z., Obst, O. (2002). Školní didaktika. Portál.

Koukolík, F. (2000). Lidský mozek. Funkčni systémy. Norma a poruchy. Portál.

Kulišt’ák, P. (2011). Neuropsychologie. Portál.

Lachout, M. (2012). Gedächtnis und Strategien zu seiner Unterstützung im FSU. In P. Besedova (Ed.), Germanistik in Theorie und Praxis. Gaudeamus.

Markowitsch, H. J. (2009). Dem Gedächtnis auf der Spur. Vom Erinnern und Vergessen. WBG.

Nakonečný, M. (2003). Úvod do psychologie. Academia.

Paulesu, E., Frith, C. D., \& Frackowiak, R. S. (1993). The neural correlates of the verbal component of working memory. Nature, 362(6418), 342-345.

Průcha, J. (2013). Moderní pedagogika. Portál.

Průcha, J., Walterová, E., \& Mareš, J. (2009). Pedagogický slovník (6.vyd.). Portál.

Sapir, E. (1964). Culture, language and personality. University of California Press.

Sedlák, F., \& Váňová, H. (2013). Hudební psychologie pro učitele. Karolinum.

Sinz, R. (1979). Neurobiologie und Gedächtnis: Neuronennetzwerke und Informationsspeicherung im menschlichen Gehirn. VEB.

Squire, L. R. (1987). Memory and Brain. University Press.

Sternberg, R. J. (2002). Kognitivní psychologie [Cognitive Psychology]. Portál 